\title{
EDUCAÇÃO AMBIENTAL E SUSTENTABILIDADE NOS CURSOS DE LICENCIATURA DA UNIVERSIDADE DO ESTADO DA BAHIA - CAMPUS VII
}

\author{
Alexsandro Ferreira de Souza Silva ${ }^{1}$ \\ Adson dos Santos Bastos ${ }^{2}$ \\ Maria José Souza Pinho ${ }^{3}$
}

Resumo: Esse artigo versa sobre a temática Educação Ambiental e Sustentabilidade nos currículos das licenciaturas de Ciências Biológicas, Pedagogia e Matemática da Universidade do Estado da Bahia, Departamento de Educação, Campus VII. É uma pesquisa qualitativa, de natureza documental. Analisamos os Projetos Pedagógicos dos Cursos, Fluxogramas dos Componentes Curriculares e os Trabalhos de Conclusão de Curso. Adotamos a análise de conteúdo como técnica de tratamento de dados. Os resultados demonstraram que a temática Educação Ambiental e a Sustentabilidade ainda não se constituem práticas inseridas de forma crítica e interdisciplinar na formação de professores deste campus.

Palavras-Chave: Educação; Currículo; Formação de Professores.

Abstract: This article discusses the theme Environmental Education and Sustainability, in the curricula of undergraduate courses in Biological Sciences, Pedagogy and Mathematics at the State University of Bahia, Department of Education, Campus VII. The qualitative research, of documentary nature, dealt with the Pedagogical Project of the Course, Flowcharts of the Curricular Components and of the Work of Conclusion of Course. We adopted content analysis as a data processing technique. The data showed that the theme Environmental Education and Sustainability are not yet practices that are inserted in a critical and interdisciplinary way in the training of teachers on this campus.

Keywords: Education; Curriculum; Teacher Training.

1 Universidade Estadual do Sudoeste da Bahia. E-mail: aleckissf@gmail.com.

Link para o Lattes: http://lattes.cnpq.br/1644109773606343

2 Universidade do Estado da Bahia. E-mail: abastos@uneb.br.

Link para o Lattes: http://lattes.cnpq.br/0489171432978588

${ }^{3}$ Universidade do Estado da Bahia. E-mail: mjpinho@uneb.br.

Link para o Lattes: http://lattes.cnpq.br/1713226099887832 


\section{Introdução}

Com 0 advento do crescimento populacional, urbanização e modernização, o consumo de bens materiais e imateriais da sociedade humana vem crescendo e desencadeando uma utilização demasiada dos recursos naturais, que causam ao meio ambiente inúmeras devastações, e consequentemente reflete em nossa sociedade. Em função dessa problemática ligada as questões ambientais, a proposta de educar nos moldes da sustentabilidade vem ganhando destaque, principalmente nas Universidades, que são os centros de formação de profissionais das diferentes áreas, inclusive de professores.

Quando se trata de Educação Ambiental (EA) nas Universidades, ainda há muito por fazer. A Educação Ambiental não é algo pronto, acabado; é uma construção, na qual possibilita a recuperação de direitos perdidos e a criação de novos direitos. Procura-se por meio dela criar uma sociedade mais igualitária, mais dinâmica e dessa maneira aperfeiçoar os valores para que o bem-estar comum, a vontade da maioria, prevaleça acima de uma minoria.

Um dos princípios da Educação Ambiental é a interdisciplinaridade. Segundo Gonçalves (1990), também nas Universidades há uma separação entre as ciências humanas e naturais, o que dificulta esta interdisciplinaridade. Deste modo, como pode existir uma educação que permeie todos os âmbitos, todas as disciplinas? Já existe a sugestão de transformá-la em disciplina, porém para isso de acordo com Sato (2003) seria preciso a ação de um educador com uma visão holística, um profissional multidisciplinar que tenha uma visão ampla com respeito às questões ambientais.

Para a autora, a EA está inserida em um sistema educacional muito mais complexo que requer uma atenção por parte da política sobre a formação de professores. Segundo ela, cobra-se dos professores apenas produtividade e não qualificação para que eles possam exercer o seu papel social. Desse modo, são oferecidos a esses profissionais apenas treinamentos curtos ou capacitações dentro do ambiente profissional.

Assim, os professores embora considerem de fundamental importância a Educação Ambiental, sentem-se despreparados para trabalhar o tema. Lima (2009) destaca que os alunos, portanto, são frutos desse despreparo acadêmico, sendo vítimas das não práticas pedagógicas do ensino.

Portanto, a formação de professores aptos a tratarem sobre as questões socioambientais é um dos objetivos propostos pelos Parâmetros Curriculares Nacionais (PCN) (BRASIL, 1997), sendo esse um dos caminhos para a conscientização da sociedade.

Essa construção é permanente e árdua, muito mais do que uma simples definição ou um simples competente curricular. As instituições de Ensino Superior (IES) brasileiras não possuem, em geral, uma política clara e definida para as questões de Educação Ambiental e Sustentabilidade. Para Loureiro (2003) o que existe são núcleos disciplinares ou multidisciplinares que, muito mais por iniciativa de um ou de alguns docentes, promovem a produção 
acadêmica, cursos de extensão, de especialização e linhas de pesquisa em programas de pós-graduação. A EA deve ser inserida no projeto de transformação do sistema educativo, da reformulação do fazer pedagógico e didático, da elaboração de modelos para a construção do conhecimento e da formação de atitudes e valores, de acordo com as necessidades dos indivíduos e da coletividade.

Esse artigo apresenta dos resultados de uma pesquisa que teve como objetivo verificar a presença da Educação Ambiental e Sustentabilidade, nos Projetos Pedagógicos dos Cursos (PPC), ementas dos componentes curriculares e Trabalhos de Conclusão de Curso (TCC) dos cursos de licenciatura em Ciências Biológicas, Matemática e Pedagogia da Universidade do Estado da Bahia, especificamente do Campus VII, Departamento de Educação, Senhor do Bonfim, BA.

\section{A Educação Ambiental na Universidade}

O ser humano transforma o meio para sua subsistência, desde o surgimento da humanidade. Com isso, hoje, o crescimento econômico-global parece ser um dos grandes desafios na construção de um desenvolvimento sustentável capaz de valorar adequadamente os recursos, tanto humanos quanto naturais, promovendo a sua perenidade. Aos conceitos de sustentabilidade e desenvolvimento sustentável, parecem caber vários significados, devido à similaridade com que são abordados e, principalmente, em virtude dos vários meios em que esses conceitos são usados.

Para Grando e Peruzzo Júnior (2013) o atual quadro preocupa, haja vista que a humanidade está exaurindo a capacidade do planeta de prover os serviços ambientais. Almeida (2007) destaca que desastres ambientais causados, principalmente, pela ação antrópica e a escassez de recursos naturais atestam, cada vez mais, a urgência de soluções que a humanidade precisa buscar para o desafio socioambiental. A falta de um modelo preciso de gestão, que concilie todas essas variáveis, só tende a agravar esse quadro, que já é grave, e tende a piora se nada for feito.

Nesse sentido, de acordo com Freitas (2011) a sustentabilidade pode ser engajada e compreendida como um novo valor moral, ético e político, na qual seja emergente na sociedade moderna. A sustentabilidade além de pressupor inovação e transformação, ela implica que o desenvolvimento de nossa sociedade está além de suas condições econômicas, consistindo na qualidade de vida dos cidadãos e a integridade ambiental.

Portanto, a sustentabilidade é fruto de um movimento histórico que passa a questionar a sociedade industrial enquanto modelo de desenvolvimento. Seria o conceito síntese desta sociedade cujo modelo se mostra esgotado. Assim, Rosa (2007) diz que a sustentabilidade pode ser considerada um conceito importado da ecologia, mas cuja operacionalidade ainda precisa ser provada nas sociedades humanas. 
Freitas (2005) relata que o termo sustentabilidade remete ao vocábulo sustentar no qual a dimensão a longo prazo se encontra incorporada. Há necessidade de encontrar mecanismos de interação nas sociedades humanas que ocorram em relação harmoniosa com a natureza. Numa sociedade Sustentável, o progresso é medido pela qualidade de vida (saúde, longevidade, maturidade psicológica, educação, ambiente limpo, espírito comunitário e lazer criativo) ao invés de puro consumo material.

Nessa perspectiva, torna-se como inspiração a definição de sustentabilidade defendida por Cabestré; Graziade; Polesel Filho (2008) quando afirmam que a sustentabilidade seria a relação entre os sistemas econômicos e os sistemas ecológicos no qual a vida humana continuaria indefinidamente e os efeitos das atividades humanas permaneceriam dentro de limites sem destruir a diversidade, complexidade e funções do sistema ecológico de suporte da vida.

E como a Universidade desempenha importante função no desenvolvimento e no progresso intelectual e social, pois é nela que o acervo dos conhecimentos se organiza, se conserva e se transmite (MANEIA, 2016). A universidade como centro de formação, desempenha papel fundamental na vida discente e da população, na qual atua no desenvolvimento do intelecto humano visando o pleno exercício da cidadania e a edificação de uma sociedade responsável e sustentável, inclusive quanto ao meio ambiente.

Isso implica o fato de que além da formação profissional técnica e qualificada a Universidade deve preparar o aluno para o pleno exercício da cidadania, ultrapassando a mera produção de conhecimento científico e tecnológico, cuidando para que a sua atividade de pesquisa vise, também, a resposta aos problemas e a busca de soluções para as necessidades da comunidade, procurando, junto ao crescimento econômico, a melhoria da qualidade de vida.

É possível, de acordo com Santos (2018) dizer que o processo de sensibilização e conscientização da comunidade acadêmica sobre a importância da sustentabilidade ambiental é uma temática que deve permear pela diversidade de disciplinas e práticas acadêmicas nas universidades, podendo ser acompanhada de uma gestão adequada, com plena cooperação entre as diversas instâncias e órgãos institucionais de acordo com as normas vigentes envolvendo todos que dela fazem parte, como os funcionários, docentes e discentes.

Além de cumprir o seu papel como pessoa jurídica dentro de um ambiente físico, a Universidade tem como missão e dever construir uma "consciência ambiental" nos futuros profissionais, graduados, que dependerá em parte da capacidade humana para inverter a crescente degradação do meio ambiente e instaurar a sustentabilidade planetária.

Abordar a temática ambiental nos currículos é de extrema importância para a formação de um sujeito crítico e responsável em relação ao ambiente que está inserido. Nesse sentido, é importante mudar a cultura, nos lares, nos 
ambientes não formais, nos ambientes formais de ensino, como por exemplo, a universidade, que por sua vez tem papel crucial na transformação dos futuros profissionais e na disseminação do conhecimento científico e no desenvolvimento de novas tecnologias favoráveis ao ambiente.

Um dos princípios da Educação Ambiental é a interdisciplinaridade. Dias (1992) reforça que a EA é apresentada de modo interdisciplinar e adequada aos currículos e conteúdos programáticos de nossas escolas. Dessa forma, destacamos como referência de Educação Ambiental, as concepções de Dias quando ele afirma que:

A Educação Ambiental é um conjunto de conteúdos e práticas ambientais orientadas para a resolução dos problemas concretos do ambiente, considerando o enfoque interdisciplinar e de participação ativa e responsável de cada indivíduo da sociedade. A Educação Ambiental deve alcançar a todas as pessoas, dentro e fora das escolas, nas associações comunitárias, religiosas, culturais, esportivas e profissionais, entre outras. (DIAS, 1992, p.77).

Assim, a Educação Ambiental é considerada ferramenta fundamental como garantia de um meio ambiente equilibrado em que o homem trabalhe visando à sustentabilidade e de forma a não a agredir. Com isso, possibilita a recuperação de direitos perdidos e a criação de novos direitos. Procura-se por meio dela criar uma sociedade mais igualitária e dinâmica, dessa maneira, aperfeiçoar os valores para que o bem-estar comum e a vontade da maioria prevaleçam acima do bem-estar de uma minoria. Essa construção é permanente e difícil, muito mais do que uma simples definição.

Conforme afirma Dias (2004), é urgente inserir a dimensão ambiental nas universidades, pois vários cursos de Educação Superior ainda não têm definidos em seus currículos à dimensão ambiental. Desse modo, muitos egressos das faculdades brasileiras podem ter uma formação fora da realidade mundial, sem uma preparação adequada para lidar com os problemas sócio ambientais desse século.

Cabe, principalmente, à universidade a tarefa de educar e, especialmente nas licenciaturas, formar multiplicadores de opinião. Aos pedagogos, matemáticos e biólogos (cursos de licenciatura do campus onde aconteceu a pesquisa), como também os demais cursos, tornar a Educação Ambiental mais presente, na formação da sociedade como um todo, e pensada não somente nos seus aspectos físicos ou biológicos, mas também em relação aos fatores socioeconômicos, ético, econômicos e políticos. Assim:

A Educação Ambiental, nas suas diversas possibilidades, abre um estimulante espaço para repensar práticas sociais e o papel dos professores como mediadores e transmissores de um 
conhecimento necessário para que os alunos adquiram uma base adequada de compreensão essencial do meio ambiente global e local, da interdependência dos problemas e soluções e da importância da responsabilidade de cada um construir uma sociedade planetária mais equitativa e ambientalmente sustentável (JACOBI, 2003, p. 204).

A EA deve estar inserida numa visão de "curriculum", e não de modo fragmentado, numa área ou disciplina; ela é mais que Ecologia, não podendo ser tratada de maneira estanque, como caráter de disciplina, mas ser interdisciplinar. (SATO, 2003; DIAS, 2004).

Essa educação é muito mais ampla, geralmente a realidade é que a universidade trata a EA apenas dentro de cursos que possuem uma característica espacial ou ambiental, como a Biologia e a Geografia. Esquecese de todos os aspectos sociais. Essa realidade precisa ser modificada, pois como produtoras de conhecimento deveríamos ser os primeiros a ter uma nova visão da dimensão ambiental no setor educacional, especialmente a universidade.

\section{Políticas de formação docente com relação a Educação Ambiental}

Os ensinamentos e as práticas pedagógicas exigem novos paradigmas da educação, necessitam de uma formação docente pautada numa Educação Ambiental crítica e emancipatória, levando os alunos a compreender a importância da preservação do meio ambiente para a qualidade de vida. Desse modo, às práticas de ensino necessitam de uma reorientação dos conteúdos das disciplinas, requerendo uma reformulação metodológica, conceitual e curricular.

Para Loureiro (2003), cabem as instituições de ensino a tarefa de levar o indivíduo a intervir na realidade, relacionando o conteúdo das disciplinas com o cotidiano e o contexto histórico em que se situa e vivenciando os valores morais condizentes com a convivência democrática e a sustentabilidade social e planetária.

Desse modo, as instituições de ensino terão como meta, o planejamento e efetivação de práticas pedagógicas que propicie aos cidadãos, uma formação ética, para que assim, intervenha na sociedade a fim de modificá-la. Compreende-se que os docentes devem ter formação necessária para atuar em sala, possibilitando que suas práticas pedagógicas se apresentem de forma emancipatória, levando os alunos a descobrir suas potencialidades para o exercício de sua cidadania. E essa prática deve acontecer desde os primeiros anos escolares. Nesta perspectiva, Loureiro (2003, p. 86) afirma que:

Desde os primeiros anos deve-se preparar cada indivíduo para compreender a situação do mundo que o rodeia, rearticulando os conteúdos das disciplinas formais (matemática, português, ciências biológicas e ciências sociais) e criando competências 
para utilizá-la no cotidiano. Esta não é uma tarefa fácil, todos os problemas pedagógicos e estruturais das escolas somam-se ao 27 grande desafio de romper com a ideologia vigente (...). Mas é, sem dúvida, um desafio que precisa ser assumido e enfrentado por todos aqueles que entendem que o direito à educação é um direito inalienável e fator de concretização da cidadania.

Porém, é valido destacar que apesar da regulamentação da Educação Ambiental nos currículos escolares e no que diz respeito à formação de professores de todos os níveis de ensino, percebe-se o distanciamento entre teoria e prática e a dicotomia para sua inserção nos processos formais de ensino. Loureiro (2003) ressalta que as Instituições de Ensino Superior (IES) brasileiras não possuem, em geral, uma política clara e definida para a Educação Ambiental.

Ainda de acordo com o autor supracitado, este panorama pode ser entendido como o resultado do desconhecimento qualificado da direção das IES sobre o tema, sua relevância e complexidade; ausência, por parte do MEC, de política de fomento a instituição e programas, que incorporem em seus projetos pedagógicos o ambiente como eixo transversal; baixa compreensão crítica e substantiva, por parte dos profissionais do ensino superior, acerca dos princípios indissociáveis da Educação Ambiental aplicados ao conjunto das disciplinas acadêmicas; baixa socialização dos materiais e documentos produzidos e de articulação entre os grupos de pesquisa.

Percebe-se claramente que não há preocupação por parte das Políticas Públicas em debater o assunto, algo que deveria ser repensado, pois, se queremos realmente construir um mundo sustentável, a prática de Educação Ambiental é fundamental para a formação de sujeitos que se sensibilize com as causas ambientais.

Em 1974, a Secretaria de Meio Ambiente - SEMA foi criada após o péssimo impacto internacional da posição do Brasil na Conferência de Estocolmo (1972), liderando os países em desenvolvimento que não queriam ver seus planos frustrados por "mais uma estratégia primeiro-mundista" para barrar o crescimento econômico daqueles que tinham mão-de-obra barata e matéria-prima abundante. (TAVOLARO, 2012).

Em 1989, a criação do IBAMA pelo governo Sarney foi consequência do aumento exorbitante das queimadas na Amazônia nos dois anos anteriores e da efervescência do debate internacional a respeito das incertezas que decorreriam de mudanças climáticas alavancadas pelo aumento exorbitante das emissões de dióxido de carbono.

Portanto, a Educação Ambiental é essencialmente necessária no âmbito educacional, tendo em vista a sensibilização dos profissionais responsáveis pela formação cidadã, desse modo, essa formação docente, dever ser algo contínuo e constante, pois, o professor capacitado em Educação Ambiental, terá atuação não somente no contexto escolar, mas para além dela. 


\section{Metodologia}

Esta pesquisa apresenta método qualitativo, afinal o estudo se volta para a compreensão de determinada realidade a partir da interpretação de um fenômeno particular (CHISTENSEN; JOHNSON, 2012). Este método se preocupa com os processos e não simplesmente com o resultado e o produto, além de oferecer 0 ambiente natural como fonte direta dos dados e 0 significado é a preocupação essencial, ou seja, vai além de uma visão relativamente simples, superficial, estética.

Para Guba; Lincoln (1994), na pesquisa que adota o método qualitativo os dados fazem referência ao contexto, além de fornecerem uma visão rica do comportamento humano. Assim, para Triviños (2007) essa abordagem nos permite compreender os sujeitos participantes como seres históricos, com vistas a analisar e caracterizar as condições nas quais ocorre todo o processo investigativo e, não somente, seus resultados e possíveis produtos.

Para Machado; Almeida (2006) os pesquisadores que utilizam os métodos qualitativos buscam explicar o porquê das coisas, exprimindo o que convém ser feito, mas não quantificam os valores e as trocas simbólicas nem se submetem à prova de fatos, pois os dados analisados são não-métricos (suscitados e de interação) e se valem de diferentes abordagens.

\section{Lócus da Pesquisa}

A pesquisa foi realizada na cidade de Senhor do Bonfim, cidade localizada no Piemonte Norte do Itapicuru; especificamente na Universidade do Estado da Bahia - UNEB/Campus VII. Esta instituição de ensino superior tem os cursos de Licenciatura em Biologia, Pedagogia, Matemática e Teatro; além de Bacharelado em Ciências Contábeis e Enfermagem.

\section{Procedimentos de produção de dados}

Foram feitos levantamento e análise de documentos dos cursos de Licenciatura em Ciências Biológicas, Pedagogia, Matemática. Vale salientar que o curso de Licenciatura em teatro não foi objeto desta pesquisa, pois ele foi implantado no ano de 2018 e, portanto, ainda não tem nenhuma turma concluída.

Para a primeira etapa de investigação documental, foram analisados os Projetos Pedagógicos dos Cursos, o qual é um documento que define as diretrizes, metas e métodos para que a instituição de ensino consiga atingir os objetivos a que se propõe. Através das análises desses documentos, foram constatadas a presença e ausência de projetos sustentáveis ou ambientais dentro dos cursos.

Em seguida, foram avaliados os fluxogramas e ementários dos Componentes Curriculares - Esse documento é como um resumo ou sinopse de determinado tema ou área. Nesse quesito foram verificados se há presença da temática Educação Ambiental e Sustentabilidade nos componentes 
curriculares. Todos os documentos analisados encontram-se disponíveis no portal Institucional da Universidade do Estado da Bahia - UNEB.

Por fim, foram analisados os Trabalhos de Conclusão de Curso. Nesta análise, o primeiro critério de seleção foi o título do trabalho. Se o título traz referências a Educação Ambiental e a Sustentabilidade, faz a leitura do resumo para confirmação da presença do conteúdo. Esses documentos encontram-se disponíveis na biblioteca do campus ou referidos colegiados.

Utilizamos a análise de conteúdo como uma das técnicas de tratamento de dados em pesquisa qualitativa. Esta técnica está calcada na proposta L. Bardin (2011) onde ela afirma que a análise de conteúdo se configura como um conjunto de técnicas de análise das comunicações, que utiliza procedimentos sistemáticos e objetivos de descrição do conteúdo das mensagens. Além disso, a análise de conteúdo constitui uma metodologia de pesquisa usada para descrever e interpretar o conteúdo de toda classe de documentos e textos (BARDIN, 2011). Essa análise, conduzindo as descrições sistemáticas, qualitativas ou quantitativas, ajuda a reinterpretar as mensagens e a atingir uma compreensão de seus significados num nível que vai além de uma leitura comum.

Essa metodologia de pesquisa faz parte de uma busca teórica e prática, com um significado especial no campo das investigações sociais. Constitui-se em bem mais do que uma simples técnica de análise de dados, representando uma abordagem metodológica com características e possibilidades próprias. Dessa forma, a utilização da análise de conteúdo prevê três fases fundamentais: pré-análise, exploração do material e tratamento dos resultados.

\section{Resultados e Discussão}

Para entendermos melhor o espelho da situação da UNEB/Campus VII refletido nos cursos de licenciatura em Ciências Biológicas, Matemática e Pedagogia, é preciso conhecer a quantidade de horas a ser cumprida em seu período de formação. O curso de Ciências Biológicas conta com uma carga horária de $3.415 \mathrm{~h}$ e nenhuma hora é dedicada à Educação Ambiental, assim como o curso de Matemática com 2.260h, já o curso de Pedagogia precisa ser cumprido $3.470 \mathrm{~h}$ e desse são dedicados $60 \mathrm{~h}$ com uma disciplina de EA. Ambos os cursos têm carga horárias bastantes satisfatórias, porém, o mínimo é dedicado as discussões ambientais ou simplesmente há uma ausência desse contexto, que discutiremos mais à frente.

Ninguém nega a importância da questão socioambiental e da Educação Ambiental. No entanto, apesar de nunca ter se falado tanto sobre elas (a questão ambiental e a educação a ela relacionada), nunca se degradou tanto como atualmente. Para Sorrentino e Biosoli (2014) os investimentos e a centralidade dessas questões nas políticas empresariais, governamentais, não governamentais, familiares e individuais ficam na retórica e não há materialização expressa e necessária mudança cultural. 
Castro (2000) nos diz que a universidade, como espaço institucional de relevância para a produção do saber e que, por isto mesmo, deveria estar à frente das transformações, vem evoluindo lentamente, não exercendo o seu papel no sentido de propiciar a mudança da realidade socioambiental.

Para esse autor, a universidade deve deixar de ser o lugar do "saber pelo saber" e congregar, em suas pesquisas, a busca de soluções socioambientais de curto, médio e longo prazo, pois a demora da produção do conhecimento e da passagem desse conhecimento para outros pode ser decisiva no sentido de prejuízos às novas gerações. Morin (2001) acrescenta que nessa reforma seja possível criar, em cada universidade, um centro de pesquisas sobre os problemas da complexidade e da transdisciplinaridade.

$O$ surgimento de programas de reflexão interdisciplinar nas universidades põe em destaque as questões ambientais, dando a elas um tratamento epistemológico complexo que é importante para a formação de pessoas que contribuam de alguma maneira, com o equacionamento da crise ambiental. Também acreditamos que a formação universitária deve possibilitar a emergência de um educador que atue a partir de novas premissas.

Após a análise do PPC dos três cursos não foram encontradas referências sobre a temática e que tratem da implementação e a inserção dos conteúdos sócios ambientes. Com isso, entendemos que os referidos cursos reforçam o que Castro (2000) já sinalizava, ou seja, que as universidades, ou grande parte, vem progredindo em passos lentos ao se tratar de investimentos na formação socioambiental.

Já nas análises dos componentes dos cursos, foram encontrados os seguintes resultado: No curso de Ciências Biológicas e Matemática não foram deparados nenhuma disciplina que trabalhasse as questões obrigatórias propostas pelo Plano Nacional de Educação relacionadas ao meio ambiente. Ressalvamos, a presença de um único componente oferecido como optativa no curso de Ciências Biológicas - Educação Ambiental (45h). No curso de pedagogia foi encontrada uma única disciplina obrigatória no $5^{\circ}$ semestre com carga horária de $(60 \mathrm{~h})$.

Ambos os cursos, independente de clausulas "ausentes" nos PPC ou a falta de disciplinas nas ementas, não os impede que ambos realizem trabalhos sobre Educação Ambiental e Sustentabilidade. Porém, não existem muitos trabalhos no campus com as temáticas. Demonstrando assim, que os estudantes não vivenciam esta discussão durante sua formação inicial. Provavelmente, essa ausência deixa os estudantes desestimulados para pesquisar sobre a temática.

As Diretrizes Curriculares Nacionais para o curso de licenciatura (Resolução CNE/CP № 1/2006) não apresenta de forma clara a Educação Ambiental, porém aconselha que os cursos fomentem estudos "de conhecimento ambiental-ecológico". O documento referencial criado pelo Ministério da Educação (MEC) em que aborda o Meio Ambiente é os Parâmetros Curriculares Nacionais, entretanto é direcionado ao Ensino 
Fundamental, ao qual apresenta a temática como tema transversal. Por outro lado, não existe nenhum documento oficial abordando a temática no Ensino Superior. Castro (2001) sugere que para esses professores que saem da universidade sem a formação básica para discutir o tema é preciso que se faça uma capacitação. De acordo com ele:

Uma capacitação pode ser feita de vários modos: cursos de curta ou longa duração, encontros periódicos, seminários, etc. No entanto, o mais indicado seria a capacitação com período de duração mais longo, com possibilidade de maior aprofundamento de questões, por meio de educação formal ou não formal, nas quais haveria uma maior sistematização dos conteúdos. O professor capacitado em Educação Ambiental deveria ser capaz de reorientar suas práticas pedagógicas e sociais não só em sua instituição escolar, como também em outros setores, comunidades, grupos, etc., visando aos objetivos já estabelecidos em Educação Ambiental. (CASTRO, 2001, p. 50)

Segundo a UNESCO (2005, p. 44), "Educação Ambiental é uma disciplina bem estabelecida que enfatiza a relação dos homens com 0 ambiente natural, as formas de conservá-lo, preservá-lo e de administrar seus recursos adequadamente". Além disso, essa discussão deve perpassar pelas questões socioambientais, ou seja, não podemos perder de vista a relação do homem com seus pares. Assim, incluir a EA nas universidades possibilita o alcance de uma aplicação com qualidade dentro das escolas. Através dessas medidas, pode-se preparar o indivíduo para exercer sua cidadania, possibilitando a ele uma participação efetiva nos processos sociais, culturais, políticos e econômicos relativos à preservação do meio, que se encontram de certa forma em crise, precisando de recuperação urgente.

Ao iniciar a pesquisa com os Trabalhos de Conclusão de Curso, podemos ter uma noção do reflexo da ausência de um PPC elaborado com propostas e parâmetros ambientais no qual, condicione o docente a trabalhar as temáticas exigidas pelo Conselho Nacional de Educação. Para Pereira e Silva (2011) o TCC é uma produção de conhecimento e de experiências formativas em que o discente se relaciona com diferentes pontos de vista e com estudos realizados anteriormente sobre o seu tema de pesquisa.

Entretanto, como obter resultados satisfatórios a respeito dos temas de Educação Ambiental e Sustentabilidade, se há uma falha no processo de formação desses futuros docentes. O reflexo da ausência de trabalhar conteúdos sobre EA e Sustentabilidade durante a formação inicial, reflete e comprovam nos resultados encontrados. Foram analisados 251 Trabalhos de Conclusão de Curso no curso de Licenciatura em Ciências Biológicas do período de 2007 a 2018. Destas, apenas 29 são referentes a Educação Ambiental ou Sustentabilidade. 
Já o curso de Pedagogia que tem em seu fluxograma uma disciplina de EA, ou seja, existem discussões sobre os temas, obteve-se um resultado inferior ao curso de Ciências Biológicas. Esse resultado mostra-se contraditório ao que se espera. Acredita-se que uma disciplina ou professor preparado para discutir questões ambientais, tendem a nortear os alunos e despertar o interesse por pesquisa que versem sobre Educação Ambiental. Embora, a falta de um profissional qualificado, pode ser a causa da ausência de pesquisas na área, não havendo incentivo ou reflexo desse profissional. Entretanto, essa estatística encontrada no curso só reforça a necessidade de se trabalhar EA de formar interdisciplinar e não isolada em uma única disciplina ou curso. Logo que foram analisados 228 trabalhos de conclusão de curso, no período de 2005 a 2018 das quais foram encontradas apenas 07 monografias com temas de Educação Ambiental ou Sustentabilidade.

Para o curso de matemática a situação é ainda mais grave. Neste curso que foram analisadas 146 Trabalhos de Conclusão de Curso do período de 2006 a 2018 e nenhum trabalho versava sobre a temática. Esse resultado nos leva a fazer uma reflexão e com isso percebemos que os estudantes do referido curso não têm ou não tiveram a oportunidade de participar de discussões e reflexões que envolvam a temática (Figura 1). Com isso, fica evidente que a Educação Ambiental e a Sustentabilidade não serão temas de discussão em suas aulas quando estiverem exercendo a docência. $O$ que aponta para a necessidade de formação continuada com o tema.

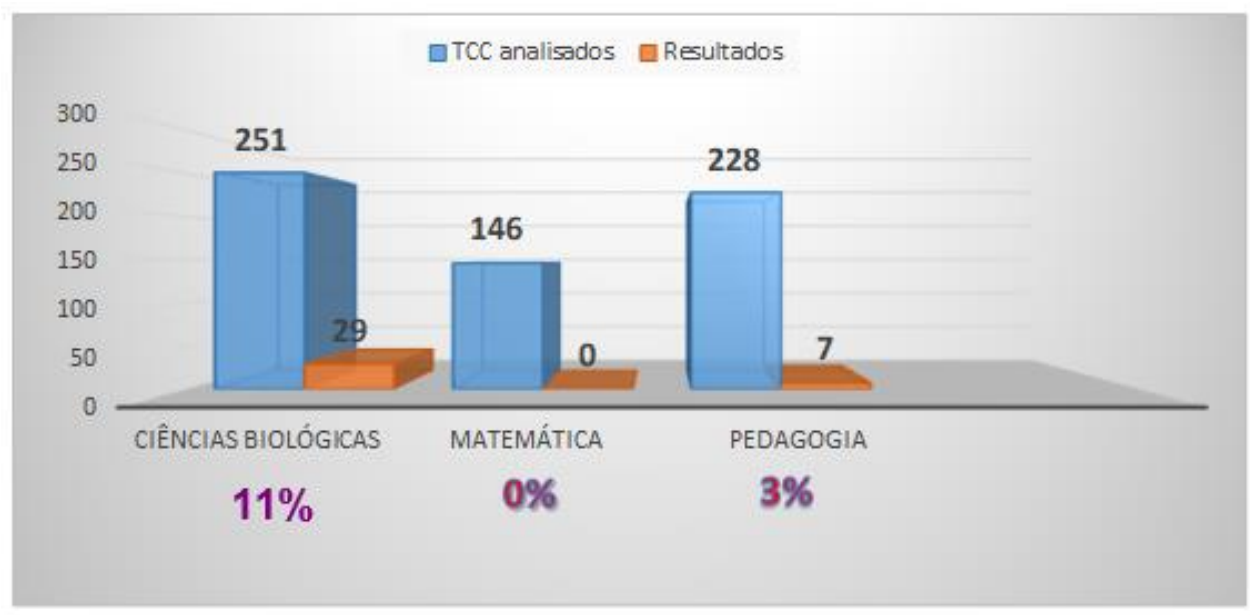

Figura 1: Trabalho de Conclusão de Curso em Educação Ambiental e Sustentabilidade Fonte: Adaptado de acordo com o acervo da biblioteca do Campus VII, 2019.

Os resultados encontrados, principalmente no curso de matemática torna-se muito preocupante, afinal, os assuntos relacionados a Educação Ambiental e Sustentabilidade são conteúdos transversais que precisam ser desenvolvidos por todos os docentes independente da área de formação, pois no final todos serão licenciados e provavelmente irão atuar em escolas.

O Artigo 9o, Parágrafo Único, da Lei no 9.795/99 sobre Educação Ambiental, diz que "[...] os professores em atividade devem receber formação 
complementar em suas áreas de atuação, com o propósito de atender adequadamente ao cumprimento dos princípios e objetivos da Política Nacional de Educação Ambiental' (BRASIL, 1999). Já o artigo $2^{\circ}$ da mesma Lei indica que a Educação Ambiental é "um componente essencial e permanente da educação nacional, devendo estar presente, de forma articulada, em todos os níveis e modalidades do processo educativo, em caráter formal e não-formal", indicando, assim, a importância da formação na área.

Vale destacar que no curso de Ciências Biológicas o período de 2009 a 2012 foi o que apresentou um maior número de trabalhos que versaram sobre a temática e de acordo com os registros isso ocorreu porque nesse período o curso tinha um professor especialista nessa discussão. Observamos que logo em seguida, o gráfico mostra uma queda nos períodos de 2013 a 2016, tais resultados é recorrente ao afastamento desse professor para o mestrado e após seu retorno havendo a remoção para outro departamento.

Já nos anos de 2017 a 2018, inicia-se um novo crescimento nas pesquisas de EA e Sustentabilidade dentro do departamento, reflexo de um novo professor especialista. Porém, esse crescimento só se estende aos cursos de Ciências Biológicas recorrente ao alcance que esse professor tem de trabalhar somente nesse determinado curso (Figura 2).

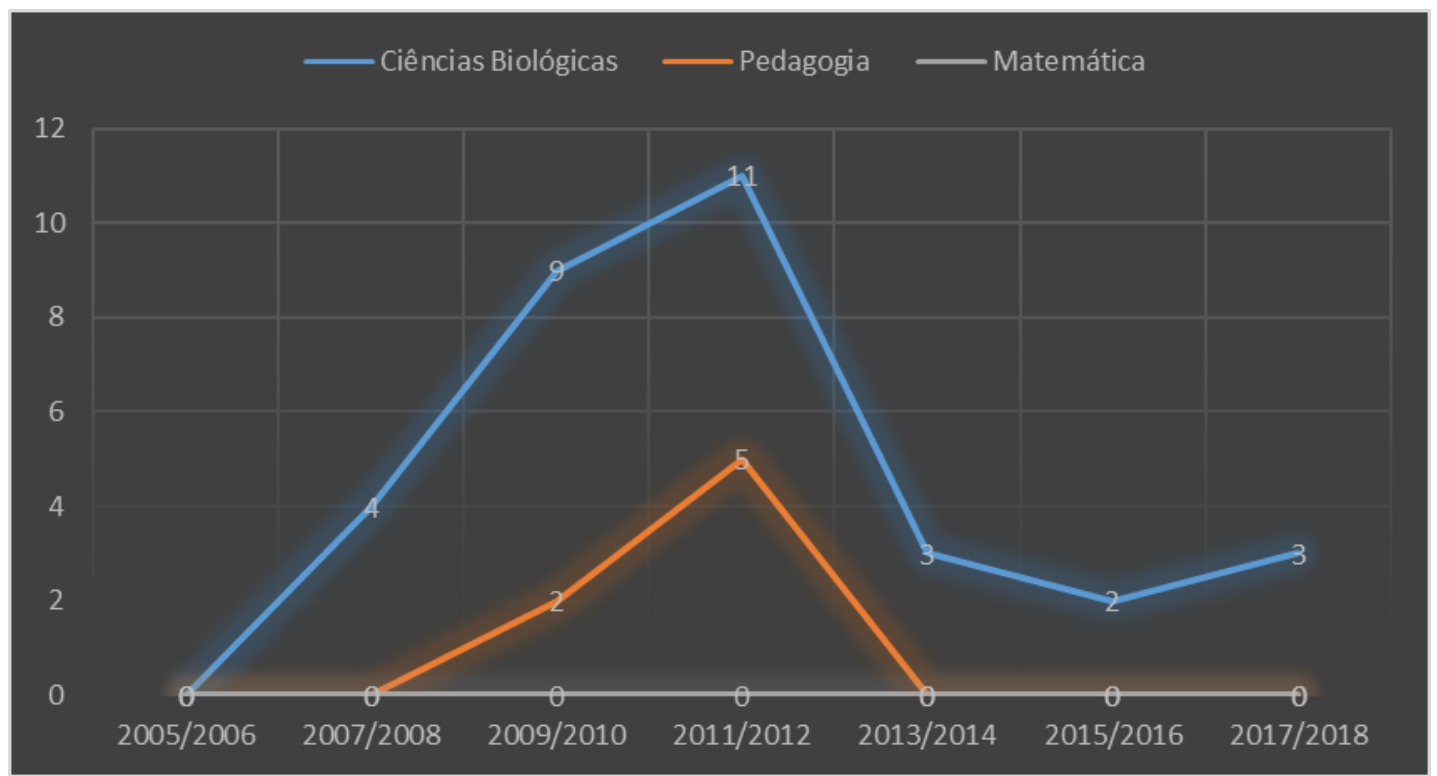

Figura 2: Demonstração do índice de TCC em EA e Sustentabilidade na UNEB/Campus 7 Fonte: Resultados a partir da análise dos TCC 
Dias (2004) esclarece que a EA é um processo permanente no qual os indivíduos e a comunidade tomam consciência do seu meio ambiente e adquirem conhecimentos, valores, habilidades, experiências e determinação que os tornem aptos a agir e resolver problemas ambientais, presentes e futuros. Porém, isso apenas será capaz quando as universidades se adequarem e der à importância necessária as temáticas ambientais.

\section{Considerações Finais}

No Brasil há uma grande necessidade de conscientização e sensibilização nas escolas desde a Educação Infantil até o Ensino Superior. É preciso incluir disciplinas específicas de Educação Ambiental no Ensino Superior, principalmente nos cursos de licenciatura. Deve-se também sistematizar o ensino sustentável onde as disciplinas em todos os níveis de ensino trabalhem interdisciplinarmente, abordando as discussões socioambientais. Após discutir os diferentes paradigmas a respeito do Projeto Pedagógico dos Cursos de Ciências Biológicas, Pedagogia e Matemática.

Ficou evidente que a Universidade do Estado da Bahia/Campus VII precisa adequar as ementas curriculares dos cursos em questão para atender as exigências das Leis vigentes. Esperamos que as instituições de Ensino Superior preparem os professores para atuar na Educação Básica com competência para discutir as questões que envolvem a temática ambiental.

\section{Referências}

ALMEIDA, F. Os desafios da sustentabilidade: uma ruptura urgente. Elsevier, Rio de Janeiro, 2007.

BARDIN, L. Análise de conteúdo. São Paulo: Edições 70, 2011.

BRASIL. Ministério da Educação Ecultura. Secretaria de Educação Ambiental. Parâmetros Curriculares Nacionais: meio ambiente e saúde. Portal MEC. Brasília. 1997. V. 9.

BRASIL. Presidência da República. Lei ํo 9.394, de 20 de dezembro de 1996. Estabelece as diretrizes e bases da educação nacional. Brasília, 1996. Disponível em: <http://www.planalto.gov.br/ccivil 03/Leis/L9394.htm> . Acesso em: 30 de agosto. 2019.

BRASIL. Encontros e Caminhos: Formação de Educadoras (es) Ambientais e Coletivos Educadores. Ministério do Meio Ambiente. Brasília, 2005.

CABESTRÉ, S.A.; GRAZIADE, T.M.; POLESEL FILHO, P. Comunicação Estratégica, Sustentabilidade e Responsabilidade socioambiental - um estudo destacando os aspectos teórico-conceituais e práticos. Anais XXXI Congresso Brasileiro de Ciências da Comunicação - Intercom. Natal, 2008.

DIAS, R. Gestão ambiental: responsabilidade social e sustentabilidade. Atlas, São Paulo, 2009.

revista brasileira educação ambiental 
DIAS, G.F. Educação Ambiental: princípios e prática. Gaia. São Paulo, 1992.399p

FREITAS, J. Sustentabilidade: direito ao futuro. Editora Fórum. Belo Horizonte, 2011, p.34.

GONÇALVES, D.R.P. Educação Ambiental e o ensino básico. Anais do IV Seminário Nacional sobre Universidade e Meio Ambiente. Florianópolis, 1990, p. $125-146$.

GUBA, E. G.; LINCOLN, Y. W. Competing paradigms in qualitative research. In: DENZIN, N. K.; LINCOLN, Y. S. (Ed.). Handbook of qualitative research. Thousand Oaks. Sage, 1994. p. 105-117.

GRANDO, G; PERUZZO JÚNIOR, L. Sustentabilidade e responsabilidade social empresarial: Uma nova proposta de ecofilosofia empresarial. Programa de Apoio à Iniciação Científica - PAIC. São José dos Pinhaes, 2012-2013

JOHNSON, B.; CHRISTENSEN, L. Quantitative, qualitative, and mixed approaches. Educational research. Thousand Oage, 2012.

LEFF, Enrique. Saber Ambiental. Petrópolis: Vozes, 2001.

LIMA, D. Projeto Político Pedagógico e Educação Ambiental uma necessária relação para a construção da cidadania. Webartigos, Paranaguá, 2009.

LOUREIRO, C.F.B.; LAYRARGUES, P.P.; CASTRO, R.S. (Org.). Sociedade e meio ambiente: A Educação Ambiental em debate. Cortez, São Paulo, 2003.

MANEIA, A. A responsabilidade ambiental da Universidade na formação humana. Revista Eletrônica em Gestão, Educação e Tecnologia Ambiental. Santa Maria, 2016, v. 20.

MACHADO, P. B. e ALMEIDA, S. A. L. Primeiro Colóquio Internacional Québec- Bahia: Formação da Pesquisa e Desenvolvimento em educação. Salvador, 2006.

PEREIRA, A. SILVA, M. O trabalho de conclusão de curso: constructo epistemológico no currículo formação, valor e importância. Laboratório de Pesquisa Multimeios: Fortaleza, 2011.

ROSA, A. Rede de governança ambiental na cidade de Curitiba e o papel das tecnologias de informação e comunicação. Dissertação de mestrado. Gestão Urbana. Paraná, 2007.

SANTOS, F. As universidades e a sustentabilidade ambiental: A sustentabilidade ambiental nas universidades brasileiras. Revista Gestão Universitária, V.10, 2018.

SATO, M. Educação Ambiental. RIMa. São Carlos, 2003.

TRIVIÑOS, A. N. Silva. Introdução à pesquisa em ciências sociais: A pesquisa qualitativa em educação. Atlas. São Paulo, 2007. 